Volume 9, No.4, July - August 2020

International Journal of Advanced Trends in Computer Science and Engineering

Available Online at http://www.warse.org/IJATCSE/static/pdf/file/ijatcse366942020.pdf

https://doi.org/10.30534/ijatcse/2020/366942020

\title{
Software implementation of a Computational Algorithm for accounting for the presence of local Superficial Heat Exchanges in Rods of variable section
}

\author{
Mukaddas Arshidinova ${ }^{1}$,Azat Tashev $^{2}$, Anarbay Kudaykulov ${ }^{3}$ \\ ${ }^{1}$ Al-Farabi Kazakh National University, Almaty, Kazakhstan,mukaddas_arshidi@mail.ru
} ${ }^{2}$ Institute of Information and Computational Technologies CS MES RK, Almaty, Kazakhstan azattash@mail.ru ${ }^{3}$ Institute of Information and Computational Technologies CS MES RK, Almaty, Kazakhstan kudaykulov2006@mail.ru

\section{ABSTRACT}

The established thermo mechanical status of a rod of limited length of variable section at simultaneous existence of local superficial heat exchanges, heat insulation and heat fluxes has been considered. At a research of a rod fundamental conservation laws of energy and square the function spline in a local coordinate system has been used.

Key words : Lengthening, axial force, sections, temperature, movement, deformation, tension.

\section{INTRODUCTION}

Consider the horizontal core of limited length $\mathrm{L}[\mathrm{cm}]$ and variable section $\mathrm{F}(\mathrm{x})\left[\mathrm{cm}^{2}\right]$. Radius of section of a core changes linearly on its length $r=a x+b[c m],(0 \leq x \leq L)$, where $a$ and $b$ are constants. The cross-sectional area of a core changes not linearly on core length as follows $\mathrm{F}(\mathrm{x})=\pi \mathrm{r}^{2}=\pi\left(\mathrm{a}^{2} \mathrm{x}^{2}+2 \mathrm{abx}+\mathrm{b}^{2}\right)\left[\mathrm{cm}^{2}\right],(0 \leq \mathrm{x} \leq \mathrm{L})$.

Physical and mechanical properties of material of a core are characterized by heat conductivity coefficients $K_{x x}\left[\frac{\mathrm{watt}}{\mathrm{cm}{ }^{\circ} \mathrm{C}}\right]$, and thermal expansion $\alpha\left[\frac{1}{{ }^{\circ} \mathrm{C}}\right]$ module of elasticity of material of a coreE $\left[\frac{k G}{c^{2}}\right]$. Let's assume that on the cross-sectional area of the left end of a core the heat flux of constant intensity is brought $\mathrm{q}_{1}\left[\frac{\mathrm{watt}}{\mathrm{cm}^{2}}\right]$. At this time on the cross-sectional area of the right endof a core the heat flux is brought by intensity $\mathrm{q}_{2}\left[\frac{\text { watt }}{\mathrm{cm}^{2}}\right]$. Local side $\operatorname{surfaces}\left(0 \leq \mathrm{x} \leq \mathrm{L}_{1}\right)$ and $\left(\mathrm{L}_{2} \leq \mathrm{X} \leq \mathrm{L}\right)$ the studied core are heat-insulated. Through a local side surface $\left(\mathrm{L}_{1} \leq \mathrm{x} \leq \mathrm{L}_{2}\right)$ core there is a heat exchange to the environment of this surface. At the same time heat exchange coefficient $h\left[\frac{\mathrm{watt}}{\mathrm{cm}^{2} \mathrm{C}}\right]$, and ambient temperature $\mathrm{T}_{\mathrm{oc}}\left[{ }^{0} \mathrm{~K}\right]$, it is necessary to define the field of distribution of temperature, three components of deformations, tension and movement. The settlement scheme of a task is provided in Figure 1

$\mathrm{q}_{1}$

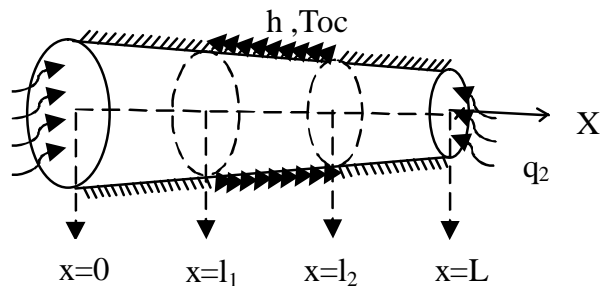

Figure 1: The settlement scheme of a task.

\section{CONSTRUCTION A QUADRATIC SPLINE FUNCTION IN THE LOCAL SYSTEMOF COORDINATES}

The investigated rod of variable cross-section and bounded length is discretized by elements of length $1=\mathrm{L} / \mathrm{n}[\mathrm{cm}]$ $[1,2]$. In this case, $\mathrm{n}$ is the number of discrete elements in the rod. Here $1<<$ L. Consider the temperature distribution field along the length of one discrete element $1[\mathrm{~cm}]$ (eg.Figure2).

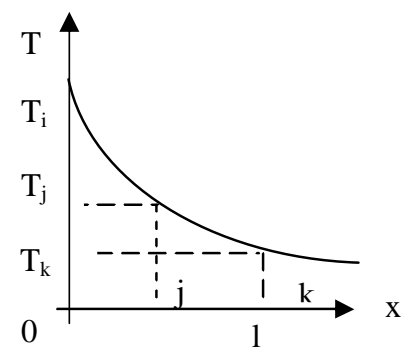

Figure 2:Temperature distribution field along the length of one discrete element. $(0 \leq x \leq l)$

In a local coordinate system $(0 \leq x \leq l)$ cross-section with the coordinate of the cross section with coordinate $x=0$, denote by i. Similarly, the cross section with the coordinate $x=\frac{l}{2}$, denote by $\mathrm{j}$. Finally, the cross section with the coordinate $x=l$, denote by $\mathrm{k}$. The temperature values in the nodes $\mathrm{i}, \mathrm{j}, \mathrm{k}$ denote $\mathrm{Ti}$, $\mathrm{Tj}$ and $\mathrm{Tk}$, respectively. The law of temperature distribution along the length of one discrete element isapproximated by a complete polynomial of the second order, that is

$$
T(>c)=C_{1} x^{2}+C_{2} x+C_{3},(0 \leq x \leq l)(1)
$$

where $C_{1}, C_{2}$ and $C_{3}$ the constants are.

At above the accepted designations it is possible to construct the following system for determination of values of constants are above $C_{1}, C_{2}$ and $C_{3}$.

$$
\left\{\begin{array}{c}
T(x=0)=C_{1} \cdot 0+C_{2} \cdot 0+C_{3}=T_{i} \\
T\left(x=\frac{l}{2}\right)=C_{1} \cdot \frac{l^{2}}{4}+C_{2} \cdot \frac{l}{2}+C_{3}=T_{j} \\
T(x=l)=C_{1} \cdot l^{2}+C_{2} \cdot l+C_{3}=T_{k}
\end{array}\right.
$$

Thus, we find that

$$
\begin{gathered}
C_{3}=T_{i}, C_{2}=\frac{4 T_{j}-T_{k}-3 T_{i}}{l}, \\
C_{1}=\frac{2}{l^{2}}\left(T_{i}-2 T_{j}+T_{k}\right)
\end{gathered}
$$


Further substituting (3) formula in (1) we will receive

$$
\begin{aligned}
& (0 \leq x \leq l)_{(4)} \\
& \text { Here we will enter the following des } \\
& \varphi_{i}(x)=\frac{2 x^{2}-3 l x+l^{2}}{l^{2}} ; \varphi_{j}(x)=\frac{4 l x-4 x^{2}}{l^{2}} ; \\
& \varphi_{k}(x)=\frac{2 x^{2}-l x}{l^{2}} ;(0 \leq x \leq l)_{(5)}
\end{aligned}
$$$$
T(x)=\frac{2 x^{2}-3 l x+l^{2}}{l^{2}} T_{i}+\frac{4 l x-4 x^{2}}{l^{2}} T_{j}+\frac{2 x^{2}-l x}{l^{2}} T_{k}
$$

Here we will enter the following designations:

These functions we will call square a spline functions in the local system of coordinates $(0 \leq x \leq l)$ [3]. These functions have the following properties

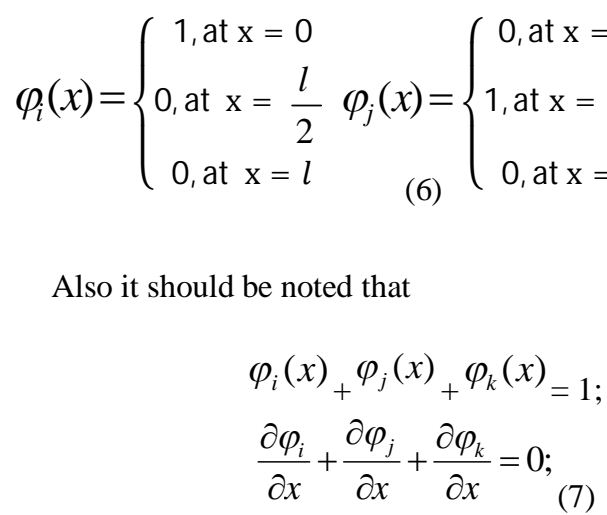

These properties square the spline of functions provides the continuity of required functions upon transition from a discrete element to next.

Using expressions (6) we will rewrite (4) in the following look:

$$
T(x)=\varphi_{i}(x) T_{i}+\varphi_{j}(x) T_{j}+\varphi_{k}(x) T_{k},(0 \leq x \leq l)_{(8)}
$$

Expression of a gradient of temperature within length of one discrete element has the following appearance.

$$
\begin{aligned}
& \frac{\partial T}{\partial x}=\frac{\partial \varphi_{i}(x)}{\partial x} T_{i}+\frac{\partial \varphi_{j}(x)}{\partial x} T_{j}+\frac{\partial \varphi_{k}(x)}{\partial x} T_{k}= \\
& =\frac{4 x-3 l}{l^{2}} T_{i}+\frac{4 l-8 x}{l^{2}} T_{j}+\frac{4 x-l}{l^{2}} T_{k}, \quad \text { (9) } \\
& \quad(0 \leq x \leq l)
\end{aligned}
$$

Similarly (8), the field of movement within length of one discrete element will have the following appearance

$$
U(x)=\varphi_{i}(x) U_{i}+\varphi_{j}(x) U_{j}+\varphi_{k}(x) U_{k},(0 \leq x \leq l)(10)
$$$$
\text { where,Ui,Uj ,Uk... - movement of sections i, j, k. }
$$

3.CREATION OF FUNCTIONALITIES OF TOTAL HEAT ENERGY FOR DISCRETE ELEMENTS OF A ROD OF VARIABLE SECTION.

Let's consider discrete elements of the studied rod of variable section with left on the right. At first we will consider the first discrete element, since the left end of a rod (eg.Figure3.) $\mathrm{q}_{1}$

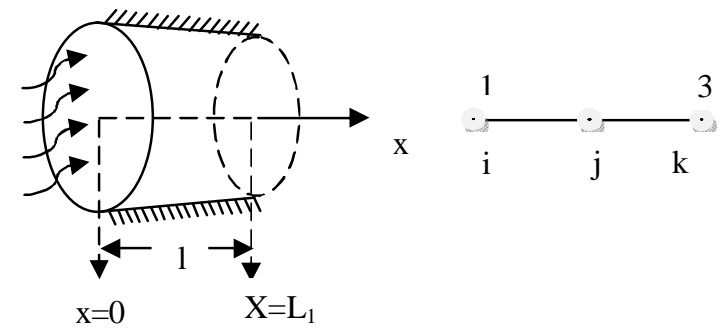

Figure 3:The first discrete element of the studied core.

For this element the functionality of total thermal energy has the following appearance [4-7]

$\quad J_{1}=\int_{F(x=0)} q_{1} T d s+\int_{V_{1}} \frac{K_{x x}}{2}\left(\frac{\partial T}{\partial x}\right)^{2} d v$
at $\mathrm{x}=0,(0 \leq x \leq l)_{(11)}$
$\mathrm{x}=\frac{l}{\text { For the first discrete element to local numbers } \mathrm{i}, \mathrm{j}, \mathrm{k}}$
correspond global numbering of hubs 1.2 and 3 .
Then, for the first discrete element of the studied core $T_{i}=T_{1} ; T_{j}=T_{2} ; T_{k}=T_{3}$;

Here the 2 and 3 knots are internal. Now, taking into account physical laws we integrate expression (11). For the first element of this expression we have

$$
J_{11}=\int_{F(x=0)} q_{1} T d s=F(x=0) \cdot q_{1} T_{i}=\pi b_{1}^{2} q_{1} T_{1}
$$

$$
\text { where }_{1}=r(x=0)=a \cdot 0+b=b \text {; }
$$

Similarly, we will consider the second integral on the volume of the first discrete element of the studied core.

$$
J_{12}=\int_{V_{1}} \frac{K_{x x}}{2}\left(\frac{\partial T}{\partial x}\right)^{2} d v=\int_{0}^{l} F(x)\left(\frac{\partial T}{\partial x}\right)^{2} d x
$$

Here it is revealed that the sum of coefficients at $T_{1}^{2}, T_{2}^{2}, T_{3}^{2}, T_{1} T_{2}, T_{1} T_{3}, T_{2} T_{3}$ will be equal to zero.

Now we will consider the second discrete element which through side surfaces there is a heat exchange to the environment (eg. Figure4).

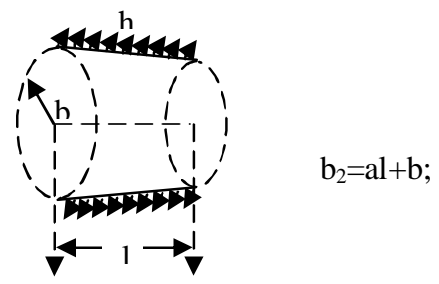

Figure 4: The second discrete element.

The functionality of total thermal energy for the second discrete element will be the following [8]

$$
J_{2}=\int_{V_{2}} \frac{K_{x x}}{2}\left(\frac{\partial T}{\partial x}\right)^{2} d v+\int_{S_{n ๓ n} 2} \frac{h}{2}\left(T-T_{o c}\right)^{2} d s
$$


where, $\mathrm{V}_{2}$-volume of the second discrete element, Sпбп2 -area of a side surface of the second discrete element.

Now we pass to the third discrete element. The side surface of this element is heat-insulated. On the cross-sectional area of the left end we will bring a heat flux intensity of $\mathrm{q}_{2}(\mathrm{eg}$. Figure5).

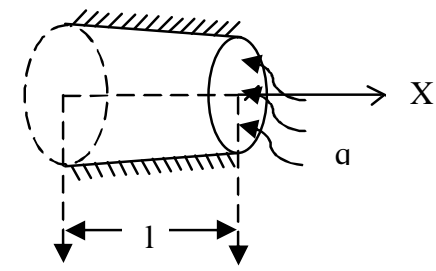

Figure 5: The third discrete element.

For the third discrete element the functionality of total thermal energy has the following appearance

$$
\mathrm{J} 3=\int_{V_{3}} \frac{K_{x x}}{2}\left(\frac{\partial T}{\partial x}\right)^{2} d v+\int_{F(x=L)} q_{2} T d s
$$

where, $\mathrm{V}_{3}$-volume of the third discrete element, $\mathrm{F}(\mathrm{x}=\mathrm{L})$ -cross-sectional area of the right end of a core $\mathrm{F}(\mathrm{x}=\mathrm{L})=$ $\mathrm{F}(\mathrm{x}=31)=\pi(a l+b)^{2}=\pi(3 a l+b)^{2}$

Then the integrated type of functionality of $J_{3}$ has the following appearance

$\mathrm{J}_{3}=\frac{\pi K_{x x}}{2}\left[\left(\frac{a^{2} l}{5}+a b_{3}+\frac{7 b_{3}^{2}}{3 l}\right) T_{5}^{2}+\left(\frac{32 a^{2} l}{15}+\frac{16 a b_{3}}{3}+\frac{16 b_{3}^{2}}{3 l}\right) T_{6}^{2}+\left(\frac{23 a^{2} l}{15}+\frac{11 a b_{3}}{3}+\frac{7 b_{3}^{2}}{3 l}\right) T_{7}^{2}\right.$ $\left.-\left(\frac{4 a^{2} l}{5}+\frac{8 a b_{3}}{3}+\frac{16 b_{3}^{2}}{3 l}\right) T_{5} T_{6}+\left(\frac{2 a^{2} l}{5}+\frac{2 a b_{3}}{3}+\frac{2 b_{3}^{2}}{3 l}\right) T_{5} T_{7}-\left(\frac{52 a^{2} l}{15}+8 a b_{3}+\frac{16 b_{3}^{2}}{3 l}\right) T_{6} T_{7}\right]+$ $\pi(a l+b)^{2} q_{2} T_{7}$

Then functionality of total thermal energy for the studied core on nodal values of temperatures $\mathrm{Ti}$, (i=1-7), we will construct the allowing system of the linear algebraic equations taking into account natural boundary conditions

$$
J=J_{1}+J_{2}+J_{3}
$$

Further minimizing this functionality on nodal values of temperatures $\mathrm{Ti},(\mathrm{i}=1-7)$, we will construct the allowing system of the linear algebraic equations taking into account natural boundary conditions [9].

Solving this system nodal values of temperature $\mathrm{Ti},(\mathrm{i}=1-7)$ are defined. On them the law of distribution of temperature on length of the studied core as follows is under construction:

For the first site of a core

$$
\begin{gathered}
T(x)=\varphi_{i}(x) T_{1}+\varphi_{j}(x) T_{2}+\varphi_{k}(x) T_{3}, \\
(0 \leq x \leq l)
\end{gathered}
$$

For the second site of a core

$$
\begin{gathered}
T(x)=\varphi_{i}(x) T_{3}+\varphi_{j}(x) T_{4}+\varphi_{k}(x) T_{5}, \\
(0 \leq x \leq l)
\end{gathered}
$$

At last for the third site of a core we have

$$
\begin{gathered}
T(x)=\varphi_{i}(x) T_{5}+\varphi_{j}(x) T_{6}+\varphi_{k}(x) T_{7}, \\
(0 \leq x \leq l)
\end{gathered}
$$

\section{DEFINITION OF THE FIELD OF TENSION AND DEFORMATIONS}

If one end of the considered horizontally located rod of variable section is rigidly jammed, then it because of existence of a field of temperature is extended. The value of lengthening is defined in compliance of the general laws of thermophysics

$\Delta l_{T}=\int_{0}^{L} \alpha T(x) d x$

where $\alpha\left[\frac{1}{{ }^{\circ} \mathrm{K}}\right]$-coefficient of thermal expansion of material of a core. $\mathrm{T}(\mathrm{x})$ the law of distribution of temperature on core length.

$$
\begin{aligned}
& \varepsilon_{T}(x)=-\alpha T(x)=-\frac{\alpha}{l^{2}}\left[\left(2 x^{2}-3 l x+l^{2}\right) T_{1}+\right. \\
& \left(4 l x-4 x^{2}\right) T_{2}+\left(4 x^{2}-4 l x+l^{2}\right) T_{3}+\left(4 l x-4 x^{2}\right) T_{4}+ \\
& \left.\left(4 x^{2}-4 l x+l^{2}\right) T_{5}+\left(4 l x-4 x^{2}\right) T_{6}+\left(2 x^{2}-l x\right) T_{7}\right] \\
& \quad 0 \leq x \leq l
\end{aligned}
$$

If both ends of the studied core are rigidly jammed, then in it arises thermo - the intense deformed state, and also axial squeezing force of $\mathrm{R}[\mathrm{kg}]$.

In case of jamming of two ends of the studied core, it is not extended and does not korachivatsya. But there is an axial squeezing force of R (eg.Figure6).

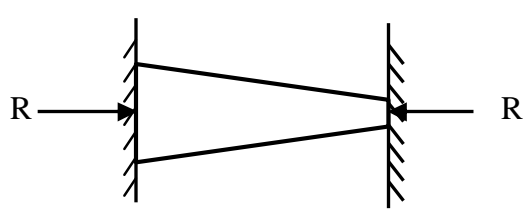

Figure 6: Rod of variable section under the influence of an axial compressive force of $\mathrm{R}$.

For determination of size of the arising axial force of $\mathrm{R}$, we find the average area of cross section

$$
\begin{aligned}
& \quad F_{\mathrm{cp}}=\frac{\int_{0}^{L} F(x) d x}{L}=\frac{\int_{0}^{L}\left(a^{2} x^{2}+2 a b x+b^{2}\right) d x}{L}= \\
& \left(\frac{a^{2} L^{2}}{3}+a b L+b^{2}\right)(23)
\end{aligned}
$$

where $F_{\text {cp }}\left[\mathrm{cm}^{2}\right]$

Let's consider a task about compression of the studied core under the influence of the axial force of R (eg.Figure 7).

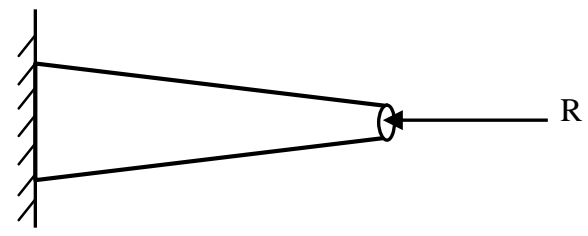

Figure 7: Compression of a rod of variable section by the axial force of $\mathrm{R}$. 
In this case the core is shortened by $\Delta l_{R}$. It is defined proceeding from the general Hooke's law.

$\Delta l_{R}=\frac{R L}{E F_{\mathrm{cp}}}(24)$

In case of jamming of two ends of the studied rod of variable section it can will be extended and to be shortened. Then we have

$$
\Delta l_{\mathrm{T}}+\Delta l_{R}=0
$$

Substituting (24) and (26) in (27) we find the size of the arising axial force

$$
\begin{gathered}
R=-\frac{E F_{\mathrm{cp}}}{L} \Delta l_{\mathrm{T}}=-\frac{\alpha E F_{\mathrm{cp}} l}{6 L}\left(T_{1}+4 T_{2}+2 T_{3}+4 T_{4}+2 T_{5}+\right. \\
\left.4 T_{6}+T_{7}\right) ;
\end{gathered}
$$

Then, in this case on length of the studied core the field of distribution of a thermoelastic component of tension [10].

$$
\begin{gathered}
\sigma_{T}(x)=\frac{R}{F(x)}=-\frac{\alpha E F_{\mathrm{cp}} l}{6 L \pi\left(a^{2} x^{2}+2 a b x+b^{2}\right)}\left(T_{1}+4 T_{2}+2 T_{3}+4 T_{4}+\right. \\
\left.2 T_{5}+4 T_{6}+T_{7}\right) \\
0 \leq x \leq l
\end{gathered}
$$

The law of distribution of a thermoelastic component of deformation $\varepsilon_{-}$is also defined by $\mathrm{T}(\mathrm{x})$ on the basis of the corresponding Hooke's law

$$
\begin{aligned}
\varepsilon(x)=\frac{\sigma(x)}{E}=- & \frac{\alpha F_{\mathrm{cp}} l}{6 L \pi\left(a^{2} x^{2}+2 a b x+b^{2}\right)}\left(T_{1}+4 T_{2}+2 T_{3}\right. \\
& \left.+4 T_{4}+2 T_{5}+4 T_{6}+T_{7}\right) ;
\end{aligned}
$$$$
0 \leq x \leq l(28)
$$

In case of jamming of two ends of the studied rod of variable section on its length there is also a field of distribution of a temperature component of deformation $\varepsilon_{-} \mathrm{T}(\mathrm{x})$. It is defined on the basis of fundamental laws of thermophysics[11,12]

$$
\begin{aligned}
\varepsilon_{T}(x)=-\alpha \mathrm{T}(x) & =-\frac{\alpha}{l^{2}}\left[\left(2 x^{2}-3 l x+l^{2}\right) T_{1}\right. \\
& +\left(4 l x-4 x^{2}\right) T_{2}+\left(4 x^{2}-4 l x+l^{2}\right) T_{3} \\
& +\left(4 l x-4 x^{2}\right) T_{4}+\left(4 x^{2}-4 l x+l^{2}\right) T_{5} \\
& \left.+\left(4 l x-4 x^{2}\right) T_{6}+\left(2 x^{2}-l x\right) T_{7}\right]
\end{aligned}
$$

Then also in compliance of the generalized Hooke's law the distribution law of a temperature component of tension longwise of the studied rod of variable section is defined

$$
\begin{aligned}
& \sigma_{T}(x)=E \cdot \varepsilon_{T}(x)=-\frac{\alpha E}{l^{2}}\left[\left(2 x^{2}-3 l x+l^{2}\right) T_{1}+\right. \\
& \left(4 l x-4 x^{2}\right) T_{2}+\left(4 x^{2}-4 l x+l^{2}\right) T_{3}+\left(4 l x-4 x^{2}\right) T_{4}+ \\
& \left.\left(4 x^{2}-4 l x+l^{2}\right) T_{5}+\left(4 l x-4 x^{2}\right) T_{6}+\left(2 x^{2}-l x\right) T_{7}\right](30)
\end{aligned}
$$

The field of distribution of elastic components of deformations $\varepsilon_{\mathrm{x}}(\mathrm{x})$ is defined on the basis of the theory of thermoelasticity

$$
\begin{aligned}
& \varepsilon_{x}(x)=\varepsilon(x)-\varepsilon_{\mathrm{T}}(x)=-\frac{\alpha F_{\mathrm{cp}} l}{6 L \pi\left(a^{2} x^{2}+2 a b x+b^{2}\right)}\left(T_{1}+\right. \\
& \left.4 T_{2}+2 T_{3}+4 T_{4}+2 T_{5}+4 T_{6}+T_{7}\right)+\frac{\alpha}{l^{2}}\left[\left(2 x^{2}-3 l x+\right.\right. \\
& \left.l^{2}\right) T_{1}+\left(4 l x-4 x^{2}\right) T_{2}+\left(4 x^{2}-4 l x+l^{2}\right) T_{3}+(4 l x- \\
& \left.4 x^{2}\right) T_{4}+\left(4 x^{2}-4 l x+l^{2}\right) T_{5}+\left(4 l x-4 x^{2}\right) T_{6}+ \\
& \left.\left(2 x^{2}-l x\right) T_{7}\right]
\end{aligned}
$$

In compliance of Hooke's law from (33) it is possible to define the distribution law of an elastic component of tension longwise of the studied rod of variable section

$$
\begin{gathered}
\sigma_{x}(x)=\sigma(x)-\sigma_{T}(x)= \\
-\frac{\alpha E F_{\mathrm{cp}} l}{6 L \pi\left(a^{2} x^{2}+2 a b x+b^{2}\right)}+\frac{\alpha E}{l^{2}}\left[\left(2 x^{2}-3 l x+l^{2}\right) T_{1}+(4 l x-\right. \\
\left.4 x^{2}\right) T_{2}+\left(4 x^{2}-4 l x+l^{2}\right) T_{3}+\left(4 l x-4 x^{2}\right) T_{4}+ \\
\left.\left(4 x^{2}-4 l x+l^{2}\right) T_{5}+\left(4 l x-4 x^{2}\right) T_{6}+\left(2 x^{2}-l x\right) T_{7}\right]
\end{gathered}
$$

\section{MOVEMENT FIELD DEFINITION LONGWISE OF THE STUDIED ROD OF VARIABLE SECTION WE WILL DESIGNATE U (X). A FIELD OF DISTRIBUTION OF THIS MOVEMENT LONGWISE OF ONE DISCRETE ELEMENT IN A LOCAL COORDINATE SYSTEM WE APPROXIMATE SQUARE A SPLINE FUNCTIONS.}

$$
\begin{gathered}
U(x)=\varphi_{i}(x) U_{i}+\varphi_{j}(x) U_{j}+\varphi_{k}(x) U_{k}=\frac{2 x^{2}-3 l x+l^{2}}{l^{2}} U_{i}+ \\
+\frac{4 l x-4 x^{2}}{l^{2}} U_{j}+\frac{2 x^{2}-l x}{l^{2}} U_{k},(0 \leq x \leq l)(33)
\end{gathered}
$$

where in the local system of coordinates in

$$
U_{i}=U(x=0) ; U_{j}=U\left(x=\frac{l}{2}\right) ; U_{k}=U(x=l) ;
$$

Then in this local system of coordinates the law of distribution of an elastic component of deformation $\varepsilon_{-} \mathrm{x}(\mathrm{x})$ is defined in compliance of a ratio of Cauchy

$$
\begin{aligned}
& \varepsilon_{x}(x)=\frac{\partial U}{\partial x}=\frac{4 x-3 l}{l^{2}} U_{i}+\frac{4 l-8 x}{l^{2}} U_{j}+\frac{4 x-l}{l^{2}} U_{k}, \\
& (0 \leq x \leq l)_{(34)}
\end{aligned}
$$

If both ends of the studied core are rigidly jammed, then $U_{1}=U_{7}=0$; Then it will be necessary to define values $U_{2}, U_{3}, U_{4}, U_{5}$ и $U_{6}$. Minimizing a functional of a potential energy of elastic deformations on these nodal values of movement we will construct the allowing system of the simple algebraic equations taking into account natural boundary conditions.

Solving this system we will define values of nodal movements. The distribution law of movement of sections of a core is determined by them. Within length of the 1 st site of a core the distribution law of movement is determined by a formula

$$
\mathrm{U}^{I}(\mathrm{x})=\frac{4 l x-4 x^{2}}{l^{2}} U_{2}+\frac{2 x^{2}-l x}{l^{2}} U_{3} ; \quad(0 \leq x \leq l)
$$

Middle the site of a core $(l \leq x \leq 2 l)$ the distribution law of movement is defined on the second as follows

$$
\begin{gathered}
\mathrm{U}^{I I}(\mathrm{x})=\frac{2 x^{2}-3 l x+l^{2}}{l^{2}} U_{3}+\frac{4 l x-4 x^{2}}{l^{2}} U_{4}+\frac{2 x^{2}-l x}{l^{2}} U_{5} \\
(0 \leq x \leq l)(35)
\end{gathered}
$$


The distribution law of movement on the last third site of a core is determined by a formula

$\mathrm{U}^{I I I}(\mathrm{x})=\frac{2 x^{2}-3 l x+l^{2}}{l^{2}} U_{5}+\frac{4 l x-4 x^{2}}{l^{2}} U_{6} ; \quad(0 \leq x \leq l)(36)$

Based on the above algorithm, ASIR 1.0 software was created, which takes into account the reliability of the software [13] and the principles of software development [14].

\section{NUMERICAL SOLUTION OF A TASK}

For an illustration of the above described method and a computing algorithm we will consider a task with the following input data:

\begin{tabular}{|l|l|l|l|l|l|}
\hline $\mathbf{L}$ & $\mathbf{l}$ & $\mathbf{a}$ & $\mathbf{b}$ & $\mathbf{b}_{\mathbf{2}}$ & $\mathbf{b}_{3}$ \\
\hline $30 \mathrm{~cm}$ & $10 \mathrm{~cm}$ & $-1 / 30$ & $2 \mathrm{~cm}$ & $5 / 3 \mathrm{~cm}$ & $4 / 3 \mathrm{~cm}$ \\
\hline
\end{tabular}

\begin{tabular}{|c|c|c|c|c|c|}
\hline $\boldsymbol{K}_{\boldsymbol{x} \boldsymbol{x}}$ & $\boldsymbol{\alpha}$ & $\boldsymbol{E}$ & $\boldsymbol{q}_{\mathbf{1}}, \boldsymbol{q}_{\mathbf{2}}$ & $\boldsymbol{h}$ & $\boldsymbol{T}_{\boldsymbol{o c}}$ \\
\hline $100 \frac{W}{\mathrm{~cm}^{\circ} \mathrm{C}} ;$ & $125 \cdot 10^{-7} \frac{1}{{ }^{\circ} \mathrm{C}} ;$ & $2 \cdot 10^{6} \frac{\mathrm{KG}}{\mathrm{cm}^{2}} ;$ & $-500 \frac{W}{\mathrm{~cm}^{2}} ;$ & $10 \frac{W}{\mathrm{~cm}^{\circ} \mathrm{C}} ;$ & $30^{\circ} \mathrm{C} ;$ \\
\hline
\end{tabular}

At these input data it is visible that the studied core is sampled by three discrete elements of identical length. At the same time lateral areas of the first and third discrete elements are completely heat-insulated. At that time through a lateral area of the second element there is a heat exchange to a surrounding medium. On the area of transverse sections of two ends of a core heat fluxes of identical intensity are brought.

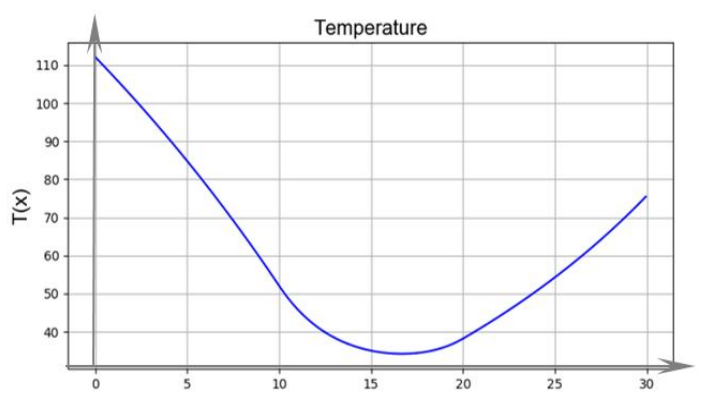

Figure 8: Temperature dependencies $\mathrm{T}$

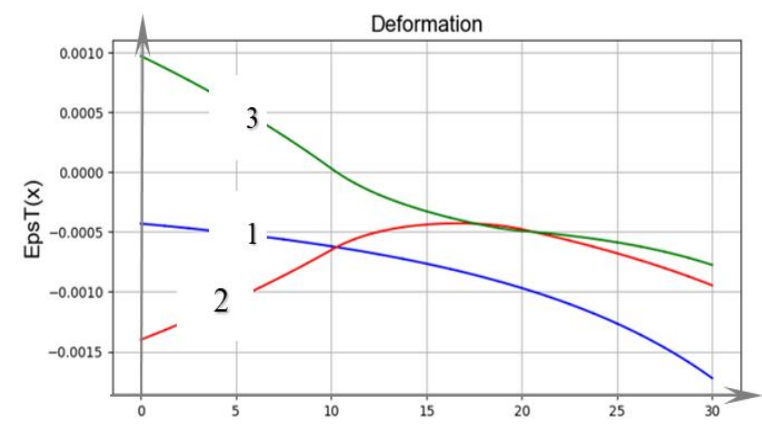

Figure 9: Dependencies deformations along the length of the rod $1-\varepsilon(x) ; 3-\varepsilon_{x}(x) ; 2-\varepsilon_{T}(x)$

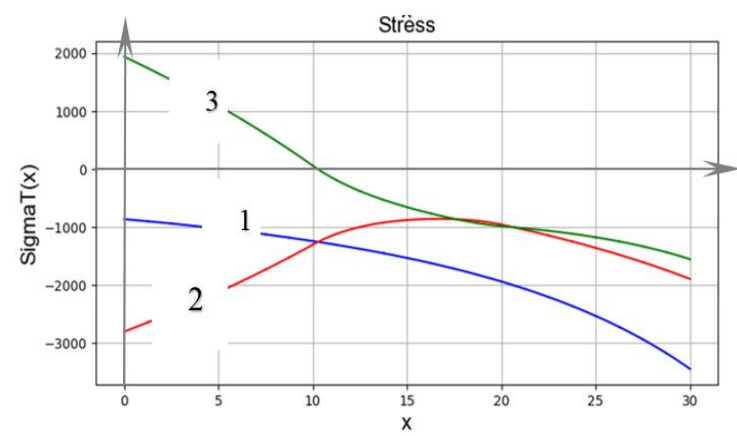

Figure 10:. Stress Dependencies along the length of the rod

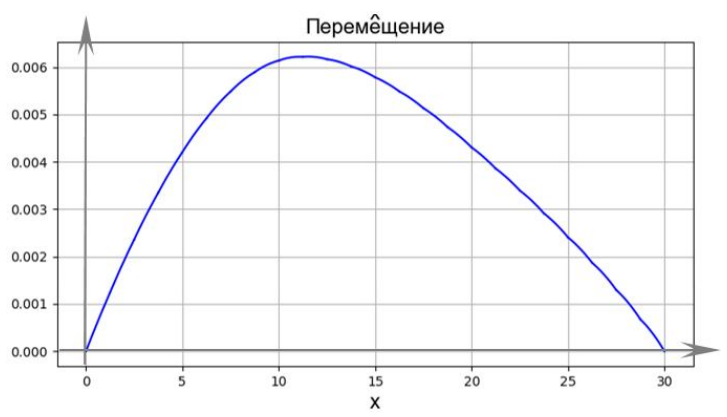

Figure 11: Dependences of displacement along the length of the rod $1-\sigma(x) ; 3-\sigma_{x}(x) ; 2-\sigma_{T}(x)$

\section{ANALYSIS OF THE OBTAINED RESULTS}

Figure8. shows the law of temperature distribution along the length of the studied rod of variable cross section. At that, the temperature values at the left end of the $\operatorname{rod}$ are $\mathrm{T}(\mathrm{x}=0)=$ $112.06{ }^{\circ} \mathrm{C}$. At that time, at the right end, $\mathrm{T}(\mathrm{x}=30 \mathrm{~cm})=75.69$ ${ }^{\circ} \mathrm{C}$. This difference is motivated by the fact that the cross-sectional area of the left end $F(x=0)=4 \pi \mathrm{cm}^{2}$, and the area at the right end $F(x=30 \mathrm{~cm})=\pi \mathrm{cm}^{2}$. Thus, $F(x=0) / F(x$ $=30 \mathrm{~cm})=4$. This means that at the left end $\mathrm{q} \square \mathrm{F}(\mathrm{x}=0)=-$ $500 \square 4 \pi=-2000 \pi(\mathrm{w})$. At the time, $\mathrm{q} \square \mathrm{F}(\mathrm{x}=30 \mathrm{~cm})=-500 \square \pi$ (w). Therefore, the temperature value at the left end exceeds 1.49 times the temperature value at the right end of the investigated rod of variable cross section. In consequence of the heat exchange with the environment of the middle part of $1 / 3$ of the rod, the temperature value in the cross section whose coordinate $\mathrm{x}=16.87 \mathrm{~cm}$ will be minimal, that is, $\mathrm{T}(\mathrm{x}=16.87$ $\mathrm{cm})=34.238{ }^{\circ} \mathrm{C}$. In addition, this is due to the fact that the radius of the cross section of the rod from the left to the right. If the left end of the rod is rigidly clamped, and the right end is free, then the investigated rod of variable cross section is extended. The magnitude of the elongation with the received initial data will

$$
\Delta l_{T}=\int_{0}^{L} \alpha T(x) d x=0,02214 \mathrm{~cm} ;
$$

If both ends of the rod are rigidly clamped, then it cannot be extended. In this case, due to the thermal expansion of the material, an axial compressive force $\mathrm{R}[\mathrm{kg}]$ arises. With our initial data, the value of this effort will be $\quad R=-10820.8148$ $\mathrm{kg}$.

Then, in this case, a steady thermo-stress-strain state arises in the rod. Figure9. shows the distribution laws for the three components of the deformation. Here curve 1 is the distribution 
law of the thermo-elastic component of deformations. It has a compressive nonlinear character along the entire length of the rod. The value as well $\varepsilon(x=0)=-0,00043$ $\varepsilon(x=30 \mathrm{~cm})=0,001722$.This means that the value $\varepsilon(x)$ at the left end of the rod is 4 times less than at the right. This process is due to the fact that the cross-sectional area of the left end of the rod 4 times more than the right. The law of temperature $\varepsilon_{T}(x)$ temperature component distribution along the entire length of the studied rod of variable cross section has a compressive and non-linear character. Moreover, its maximum value is observed at the left end of the rod $\varepsilon_{T}(x)=-0,0014$. There is a monotonous reduction $\varepsilon_{T}(x)$ to the cross section of the rod, the coordinate of which is $\mathrm{x}=16.25$ cm. Here $\varepsilon_{T}(x=16,25)=-0,00042854$ Thisis due to heat exchange through the side surface of the middle section of the rod with the environment. Then again $\varepsilon_{T}(x)$ it has a slightly increasing nature, and $\varepsilon_{T}(x=30 \mathrm{~cm})=-0,000964619$. In the law of distribution $\varepsilon_{T}(x)$ it is revealed that time $\varepsilon_{T}(x=0) / \varepsilon_{T}(x=L=30 \mathrm{~cm})=1,4804$.

This is due to the fact that the cross-sectional area of the left end of the studied rod is 4 times larger than the right. In contrast to other laws, the distribution of elastic component deformations along the length of the studied rod of variable cross section has a sign-variable character. In particular $\varepsilon_{x}(x)$, in the area of the $0 \leq x \leq 10 \mathrm{~cm}$ rod has a tensile character. For the rest $10 \leq x \leq L=30$, see the section of the rod it also has a compressive character. In general $\varepsilon_{x}(x)$, it also has a nonlinear form.

Figure10.shows the distribution law for the thermo-elastic $\sigma$ (x) and $\sigma \mathrm{T}(\mathrm{x})$ and elastic $\sigma \mathrm{x}(\mathrm{x})$ components along the length of the studied rod of variable cross section. From Figure. 9-10., it can be seen that they are proportional to the corresponding components of the deformation. In this case, the proportionality coefficient is the modulus of elasticity of the material of the $\operatorname{rod} \mathrm{E}=2 \square 106\left[\frac{\kappa G}{\mathrm{~cm}^{2}}\right]$. Finally, Figure11. shows the distribution field of the displacement of sections of the investigated rod of variable section. It can be seen from the figure that all sections move from left to right in the direction of the axis Ox. This is due to the fact that the cross-sectional area of the left end of the rod where the heat flux of constant intensity $\mathrm{q}$ is applied is 4 times larger than the right one. The largest displacement amplitude corresponds to the cross section of the rod whose coordinate is $\mathrm{x}=11.25 \mathrm{~cm}$. This is due to the occurrence of a large temperature $\mathrm{T}(\mathrm{x}=0)=112.059^{\circ} \mathrm{C}$ at the left end of the investigated rod of variable cross section.

\section{CONCLUSION}

Based on the fundamental laws of energy conservation in combination of quadratic spline functions, a method, computational algorithm and software in Python are developed for a full study of the steady thermo-stress-deformed state of a variable cross-section rod with simultaneous presence of local heat fluxes, heat exchange and thermal insulation. With specific initial data, the magnitude of the rod elongation in the case of a free one end is calculated. In the case of pinching the two ends of the rod, the laws of temperature distribution, thermoelastic temperature and elastic components of deformations, stresses, as well as displacements are determined. The magnitude of the resulting axial force is calculated. Relevant patterns have been identified and they are also due to physical laws.

All the solutions obtained satisfy the fundamental laws of energy conservation; therefore, they are distinguished by high accuracy. It is assumed that the developed methods, the computational algorithm and the software package in Python will be useful in the design of power plants, internal combustion engines, jet engines.

Acknowledgments: This work has been supported by Kazakhstan Ministry of Education and Science via Research Grant Scheme№ AP05131093.

\section{REFERENCES}

1. Larry J. Segerlind. Applied Finite Element Analysis. Jhon Willey and Sons,Inc. NewYork/ London/ Sydney/ Toronto,1976.- P.392.

2. Carslaw H.S., Jaeger J.C. Conduction of Heat in Solids. Oxford University Press, London,1986 -P.526.

3. Timoshenko S., Goodyear J. N. Theory of Elasticity. McGRAW-Hill. Book. Company. Inc., 1987. - P.567.

4. Zienkiewicz O.C. The method in Engineering science. Butterworth-Heinemann.

Oxford-Auckland-Boston-Johannesburg-Melburne-New Delhi, 2000. - P.690.

5. Maugin, G.A. The saga of internal variables of state in continuum thermo-mechanics // Mechanics Research Communications - 2015. - P.79.

6. Tashenova, Z.Nurlybaeva, E.Kudaykulov, A. Method preparation and solution algorithm for resolving stationary problem of a rod under thermo - stressed condition restrained at both ends affected by heat exchange and heat flows //2012 International Conference on Advanced Material and Manufacturing Science, ICAMMS 2012; Beijing; China.

7. Kudaykulov A., Zhumadillayeva A. Numerical simulation of temperature distribution field in beam bulk in the simultaneous presents of heat insulation, heat flux and heat exchange // Actaphysicapolonica A, 2016. - pp. 335-336. https://doi.org/10.12693/APhysPolA.130.335

8. MuheyatNiyazbek, KuenssauleTalp, Kudaykulov A.K. Computer and Mathematical Modeling of Thermomechanical Processes in Element of Constructions. Acta Scientiarum Naturalium Universitatis Nankaiensis, Vol 50 . № 3. 2017, Tianjin, China.

9. KudaykulovA., Tashev, A.A., Askarova, A.A computational algorithm and the method of determining the temperature field along the length of the rod of variable cross section //Open Engineering, 8(1), 2018. - pp. 170-175. https://doi.org/10.1515/eng-2018-0020

10. Krieth, F. Principles of Heat Transfer, 3-rd ed.. . Index Educational Publishers, N. Y. 1977.- P.150.

11. Biot, M.A. Thermoelasticity and irreversible thermodynamics // Journal of Applied Physics, 27 (3), 1956.- pp.240-253.

12. Presley, M.A., Christensen, P.R.Thermal conductivity measurements of particulate materials 1. // Journal of Geophysical Research E: Planets, 102 (E3). 1997. - pp. 6535-6549. 
https://doi.org/10.1029/96JE03302

13. MayuriH.Molawade, Dr. Shashank D. Joshi. Software reliability prediction using Knowledge Engineering approach // International Journal of Advanced Trends in Computer Science and Engineering . Volume 8, No.6, 2019. - pp.2768-2772.

https://doi.org/10.30534/ijatcse/2019/14862019

14. Sandeep Dalal, Kamna Solanki, Sudhir, Diksha. Exploring the Essentials and Principles of Software Development// International Journal of Advanced Trends in Computer Science and Engineering. Volume 8, No.6 .2019. pp.3504-3510.

https://doi.org/10.30534/ijatcse/2019/129862019 